\title{
AEROBIC EXERCISE INCREASES CATALASE ACTIVITY AND DECREASED LEVELS OF LEPTIN AND TNF $\alpha$ IN PATIENTS WITH LIVER DISEASE
}

FJ Vílchez-López ${ }^{1}$, Marta Rivas-Rivas², Isabel Mateo-Gavira ${ }^{1}$, Claudio Rodríguez-Ramos³, Manuel Romero-Gómez4

1) Endocrinology, Puerta del Mar Hospital, Cádiz, Spain. 2) Digestive, Puerto Real Hospital, Cádiz, Spain. 3) Digestive, Puerta del Mar Hospital, Cádiz, Spain. 4) Digestive, Valme Hospital and Ciberehd, Sevilla, Spain.

\section{INTRODUCTION}

Both insulin resistance and oxidative stress are implicated in the pathophysiology of various diseases such as type 2 diabetes mellitus, atherosclerosis or liver disease. Furthermore, the uncoupling protein-1 (UCP1) is involved in induced thermogenesis, related to the pathogenesis of obesity and diabetes. The aim of this study was to assess the impact of aerobic exercise on the inflammatory profile in patients with chronic hepatitis C.

\section{METHODS}

We designed an experimental prospective (before-after) study that included patients with chronic hepatitis $C$ and insulin resistance but without associated metabolic syndrome. An individualized program of aerobic exercise ( 3 sessions of 60 -minute/week) for 16 weeks was designed. Electrical bioimpedance analysis was performed (TBF-612 Tanita). Variables were determined (antioxidant markers and adipokines) before and after the intervention. Serum leptin and TNF-alpha concentrations were measured using commercial kits for ELISA (Immunotech, Coulter Corp., Westbrook, MA, USA). The catalase activity was inflammatory cytokines monitored with a commercial kit (Cayman Chemicals, Michigan USA).

\section{RESULTS}

A total of 34 patients were included. The mean age was $46.8 \pm 5$ years and 22 were male $(65 \%)$. The mean baseline BMI was $25.7 \pm 3.5 \mathrm{~kg} / \mathrm{m} 2$ and excess weight of $6.17 \pm 6.67 \mathrm{~kg}$. Adherence to the exercise program was $88 \%$. After 16 weeks of the exercise program, a significant increase in catalase enzyme levels $(20.37 \pm 1.32 \mathrm{vs.} 27.33 \pm 1.94 \mathrm{mmol} / \mathrm{min}-1 / \mathrm{mL}-1, \mathrm{p}=0.005)$ and a decrease of leptin $(14,500 \mathrm{vs} 11,500 \mathrm{pg} / \mathrm{mL}, \mathrm{p}<0.05)$ and TNF $\alpha(0.65 \mathrm{vs} 0.05 \mathrm{pg} / \mathrm{mL}, \mathrm{p}<0.05)$ levels were detected. On the other hand, the concentration of uncoupling protein-1 (UCP1) showed a statistically significant increase after exercise (305.2 vs $510.5, p<0.05)$.

Table 1. Evolution of bioimpedance analysis variables

\begin{tabular}{|l|c|c|c|}
\cline { 3 - 4 } \multicolumn{1}{c|}{} & Baseline & Week 16 & Sig. $(\mathrm{p})$ \\
\hline Body weight $(\mathrm{kg})$ & 73.6 & 73.4 & 0.703 \\
\hline Fat weight $(\mathrm{kg})$ & 14.5 & 13 & $\mathbf{0 . 0 1 1}$ \\
\hline Muscle weight $(\mathrm{kg})$ & 30 & 32 & $\mathbf{0 . 0 1 2}$ \\
\hline Bone weight $(\mathrm{Kg})$ & 11.2 & 11.2 & 0.186 \\
\hline Overweight $(\mathrm{kg})$ & 7 & 5 & $<0.001$ \\
\hline
\end{tabular}

Figure 2. Leptin levels

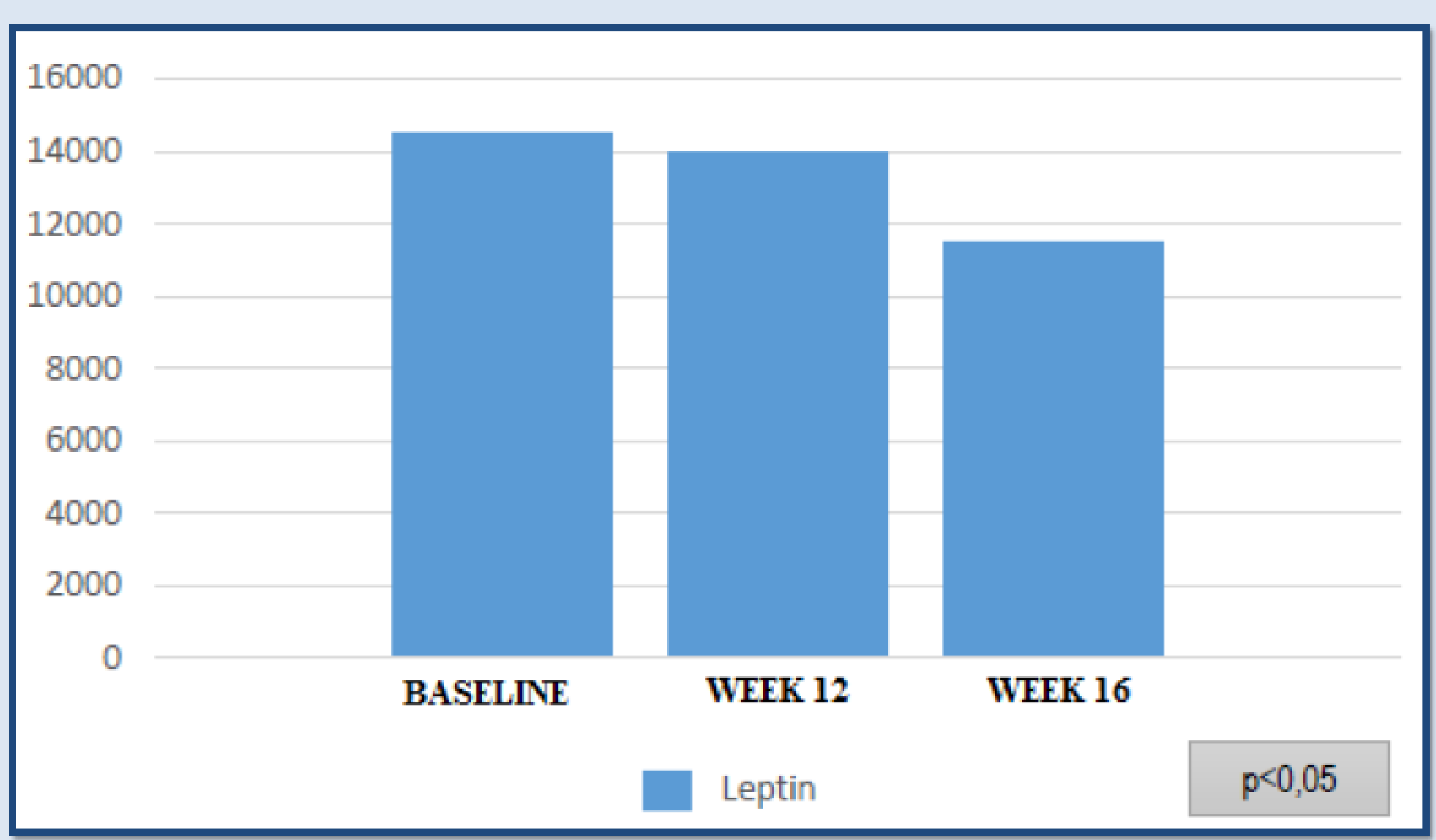

Figure 4. Uncoupling protein-1 levels

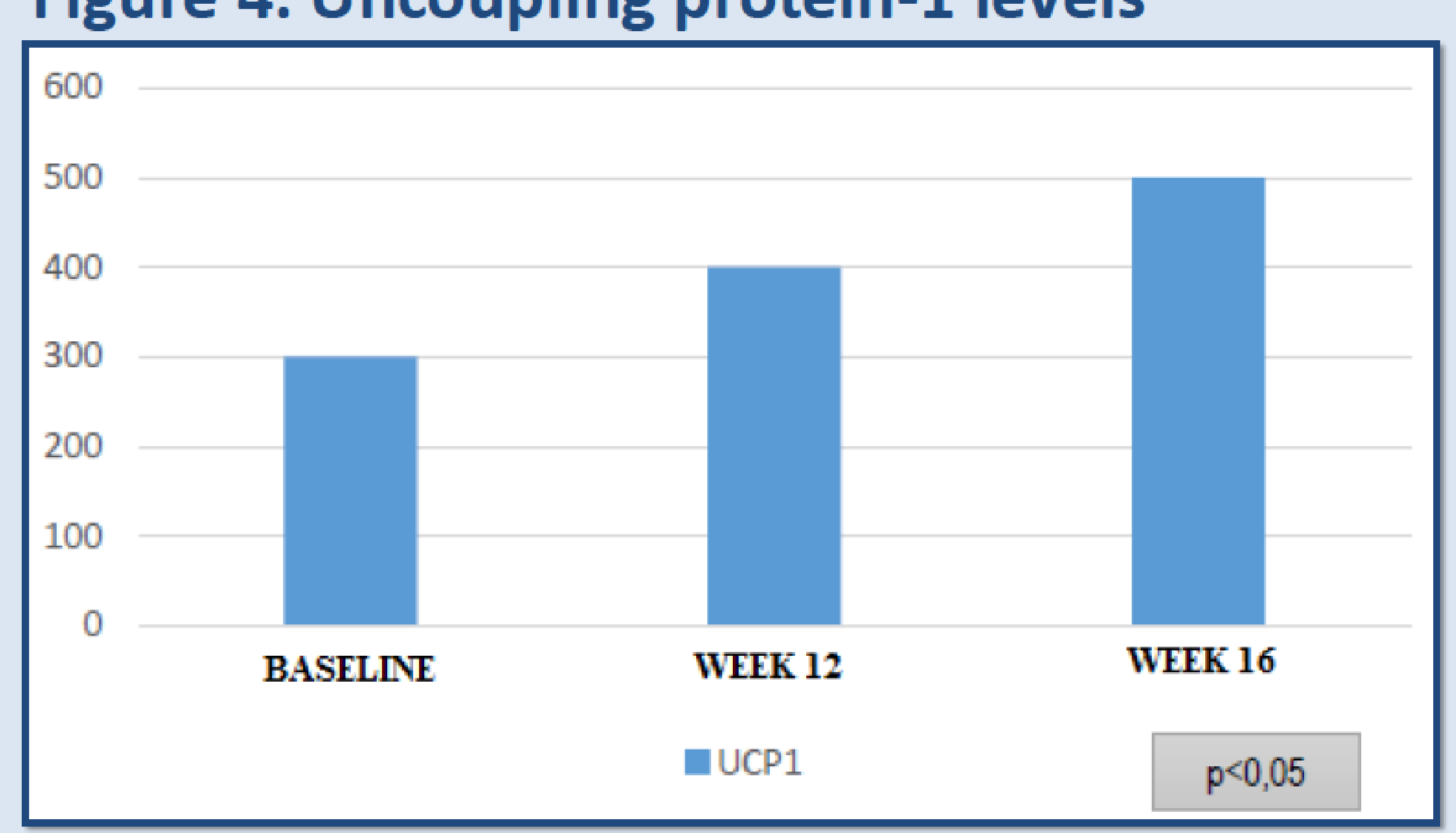

Figure 1. Increase in catalase enzyme levels

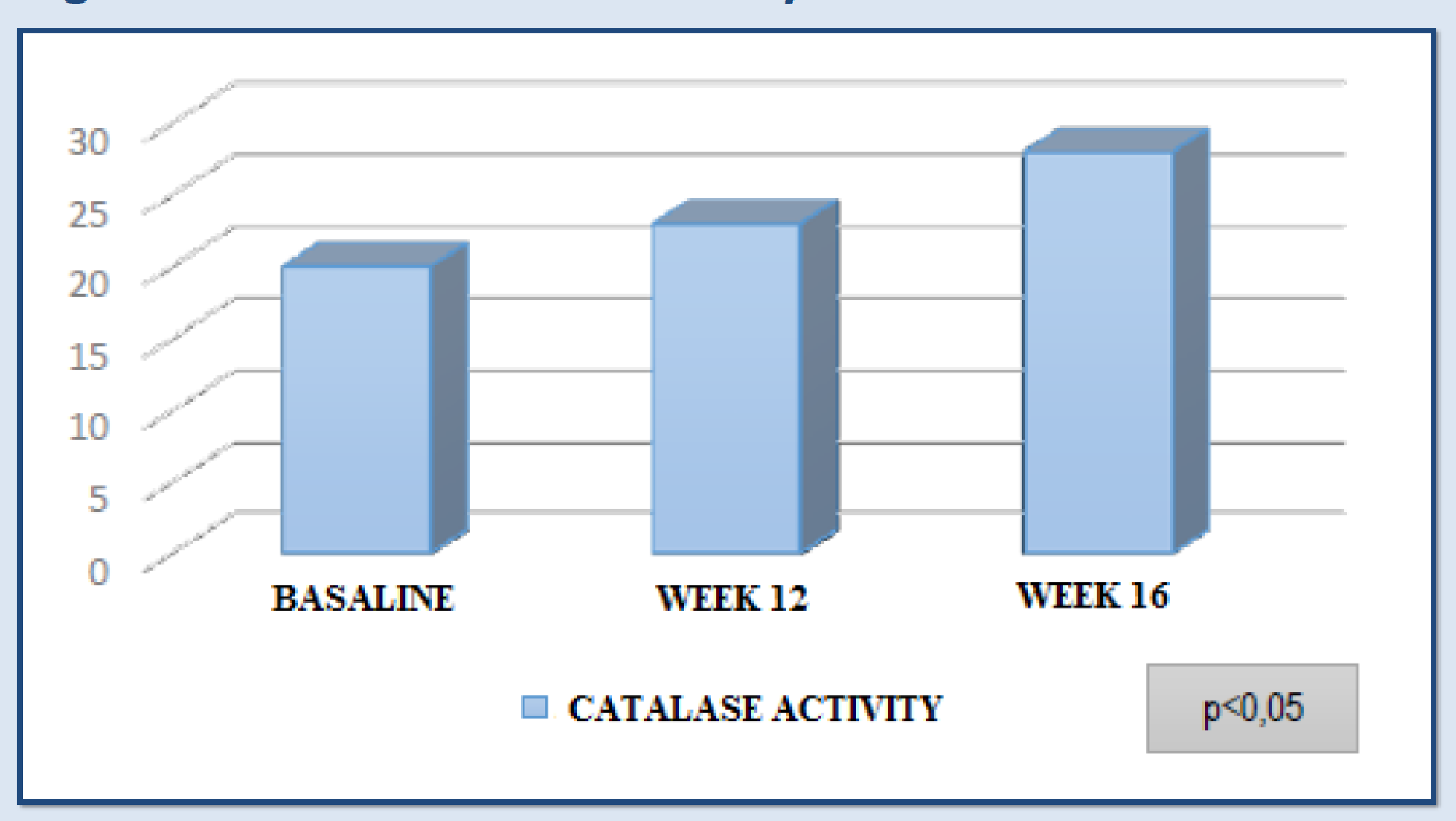

Figure 3. TNFa levels

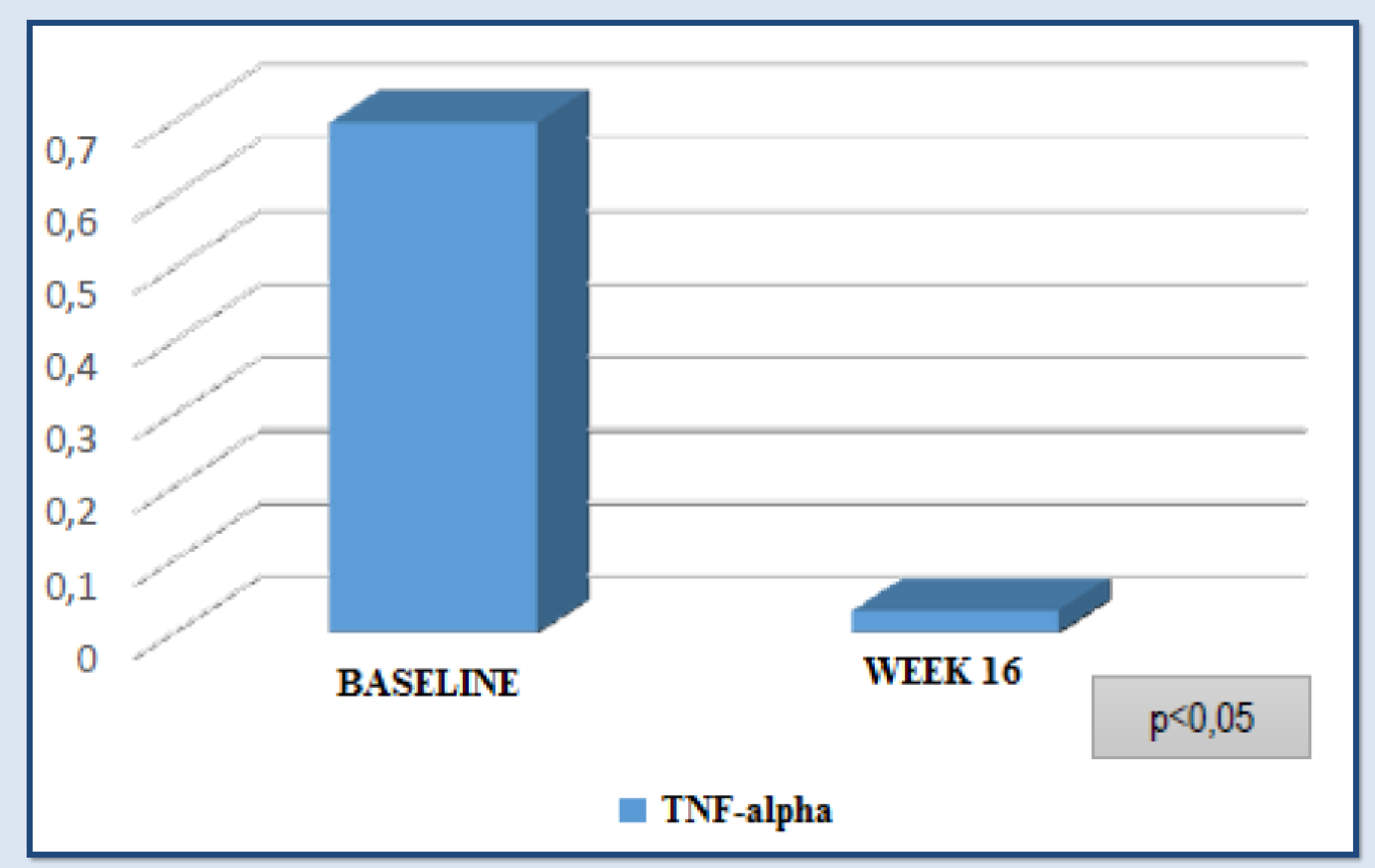

\section{CONCLUSIONS}

In our series, the prescription of an individualized aerobic exercise program, controlled and monitored for 16 weeks, improved antioxidant status and decreased levels of proinflammatory cytokines and adipokines in patients with chronic liver disease and insulin resistance. 